\title{
Blueberry Cultivars of North America
}

James N. Moore

Additional index words. Vaccinium corymbosum, V. ashei, V. angustifolium, fruit breeding, highbush blueberry, rabbiteye blueberry, southern highbush blueberry, half-high blueberry, low-chill highbush blueberry

Summary. The blueberry cultivar situation in North America is undergoing rapid change. Attempts to grow blueberries in non-traditional areas, and increased biotic and abiotic challenges in traditional production areas, are fueling the search for superior, adapted cultivars. This survey of all blueberry-producing states/provinces in the United States and Canada provides the current status and projected trends in blueberry cultivar use in North America. Most $(86 \%)$ of current hectarage is comprised of 25 northern highbush, 10 rabbiteye, and two southern highbush cultivars. 'Bluecrop' is the dominant northern highbush cultivar, with $35 \%$ of the highbush area, while 'Tifblue' occupies $40 \%$ of the rabbiteye area. Some historically important cultivars, such as 'Jersey', 'Weymouth', and 'Woodard' are in decline. New cultivars of all blueberry types are beginning to have a positive impact on the blueberry industry.

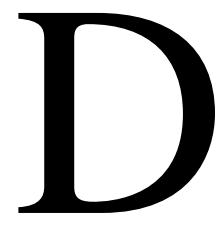
ata were collected on blueberry cultivars grown in the United States and Canada as part of a 1992 comprehensive survey questionnaire on the blueberry industry of North America (Moore, 1993). Information on cultivars was received from 35 states and four Canadian provinces. All major blueberry-producing states and provinces responded; therefore, the data reported herein can be considered to be essentially complete for the commercial cultivated blueberry industry.

Recent surveys of northern highbush (Vaccinium corymbosum L.) (Hanson and Hancock, 1990), rabbiteye (V. ashei Reade) (Spiers, 1990), half-high (V. corymbosum $\times V$. angustifolium) (Finn et al., 1990), and lowchill highbush (mixed parentage) (Lyrene, 1990) cultivars have been published. Generally, the results of the present survey agree with those reports, although newly released cultivars now are beginning to have an impact and new trends in cultivar use by the blueberry industry are beginning to appear. This report provides the current blueberry cultivar situation in each producing state and province in the United States and Canada.

Department of Horticulture and Forestry, University of Arkansas, Fayetteville, AR 72701.

I thank the many research and extension persons who provided the data on which this report is based. Published with the approval of the Director, Arkansas Agricultural Experiment Station. The cost of publishing this paper was defrayed in part by the payment of page charger. Under postal regulations, this paper therefore must hereby be marked advertisement solely to indicate this fact.

${ }^{i}$ Distinguished Professor. 
Respondents were asked to estimate the current blueberry production area in their state/province, list the five most popular cultivars with the percentage of area planted to each, and to indicate whether each cultivar was increasing, decreasing, or stable in popularity. A total of 25 northern highbush (including five half-high cultivars), 10 rabbiteye, and two southern highbush cultivars were reported in the survey. The listed cultivars account for $86 \%$ of the cultivated blueberry hectarage in North America.

The hectarage of cultivated blueberries in each state and province and the major cultivars being grown are shown in Table 1 . As expected, there is a wide diversity of culti- vars depending on geographic location. The more cold-hardy northern highbush (Vaccinium corymbosum L.) cultivars are predominant in the northern United States and Canada, while rabbiteye ( $V$. ashei Reade) cultivars are found in several southern states. Minnesota hectarage is planted exclusively to half-high blueberries, and new southern highbush (lowchill highbush) cultivars are emerging in several southern states.

The area planted to each cultivar and the current trend in cultivar popularity is shown in Table 2. A striking feature of this table is the dominance of 'Bluecrop' in northern highbush blueberry production. 'Bluecrop' occupies $35 \%$ of the northern highbush area

Table 1. Major blueberry cultipars in states/provinces in the United States and Canada.

\begin{tabular}{|c|c|c|}
\hline $\begin{array}{l}\text { State or } \\
\text { province }\end{array}$ & $\begin{array}{c}\text { Production } \\
\text { area (ha) }\end{array}$ & Major cultivars ${ }^{2}$ \\
\hline Alabama & 195 & Tifblue $(60, \mathrm{I}) ;$ Climax $(20, \mathrm{D})$, Premier $(10, \mathrm{I}) ;$ Brightwell $(5, \mathrm{I}) ;$ Woodard $(5, \mathrm{D})$ \\
\hline Arkansas & 524 & Bluecrop $(70, \mathrm{I})$; Collins (12,D); Bluejay $(8, \mathrm{I}) ;$ Blueray $(5, \mathrm{~S})$; Elliott $(5, \mathrm{~S})$ \\
\hline Connecticut & 81 & Blueray $(20, S)$; Berkeley $(17, \mathrm{D})$; Bluecrop $(15, \mathrm{I}) ;$ Collins $(11, \mathrm{~S})$; Bluetta $(4, \mathrm{D})$ \\
\hline Delaware & 26 & Blueray $(S) ;$ Earliblue $(S)$; Bluecrop $(S)$; Bluetta $(S)$ \\
\hline Florida & 853 & Sharpblue $(25, \mathrm{I})$; Climax $(20, \mathrm{~S})$; Beckyblue $(10, \mathrm{D}) ;$ Alicchlue $(10, \mathrm{D})$; Powderblue $(10, \mathrm{I})$ \\
\hline Georgia & 1668 & Tifblue $(44, \mathrm{~S}) ;$ Climax $(24, \mathrm{I}) ;$ Woodard $(8, \mathrm{D}) ;$ Brightwell $(7, \mathrm{I}) ;$ Delite $(2, \mathrm{D})$ \\
\hline Idaho & 40 & Bluecrop; Blueray; Northland; Patriot; Earliblue \\
\hline Illinois & 81 & Earliblue (D); Jersey (D); Bluecrop (S); Blueray (S); Elliott (I) \\
\hline Indiana & 304 & Jersey $(37, D)$; Bluecrop $(23, S)$; Blueray $(13, S)$; Berkeley $(6, D)$; Coville $(4, D)$ \\
\hline Iowa & 2 & Patriot $(33, \mathrm{I}) ;$ Blueray $(33, \mathrm{I}) ;$ Northbluc $(33, \mathrm{I})$ \\
\hline Kansas & 3 & Bluecrop $(35, S)$; Blueray $(30, S)$; Collins $(25, S) ;$ Patriot $(8, S)$; Northsky $(2, S)$ \\
\hline Kentucky & 18 & Earliblue $(30, \mathrm{D})$; Blueray $(30, S)$; Berkeley $(15, \mathrm{~S}) ;$ Darrow $(10, \mathrm{~S})$; Patriot $(5, \mathrm{D})$ \\
\hline Louisiana & 163 & Tifblue $(60, S) ;$ Climax $(25, \mathrm{~S}) ;$ Premier $(5, \mathrm{~S}) ;$ Brightwell $(5, \mathrm{I}) ;$ Woodard $(2, \mathrm{D})$ \\
\hline Maryland & 65 & Bluecrop $(50, S)$; Blueray $(10, S) ;$ Earliblue $(10, \mathrm{I}) ;$ Spartan $(10, \mathrm{I}) ;$ Elliott $(10, \mathrm{I})$ \\
\hline Massachusetts & 304 & Bluecrop $(33, \mathrm{I})$; Berkeley $(25, \mathrm{~S})$; Earliblue $(10, \mathrm{D}) ;$ Blueray $(10, S) ;$ Coville $(10, S)$ \\
\hline Michigan & 6885 & Jersey $(40, \mathrm{D}) ;$ Bluecrop $(30, \mathrm{I}) ;$ Rubel $(8, \mathrm{D})$; Elliott $(7, \mathrm{I}) ;$ Blueray $(4, \mathrm{~S})$ \\
\hline Minnesota & 32 & Northblue $(80, \mathrm{I}) ;$ Northcountry $(15, \mathrm{~S}) ;$ St. Cluud $(4, \mathrm{I}) ;$ Northsky $(1, \mathrm{D})$ \\
\hline Mississippi & 450 & Tifblue $(40, \mathrm{D}) ;$ Premier $(20, \mathrm{I}) ;$ Brightwell $(20, \mathrm{I}) ;$ Climax $(10, \mathrm{D})$ \\
\hline Missouri & 122 & Bluecrop $(30, \mathrm{~S}) ;$ Blueray $(30, \mathrm{~S})$; Collins $(15, \mathrm{D})$; Patriot $(10, \mathrm{I})$; Elliott $(8, \mathrm{I})$ \\
\hline Nebraska & 1 & Bluecrop; Blueray; Jersey; Patriot; Spartan \\
\hline New Hampshire & 664 & Bluecrop $(20, D) ;$ Blueray $(20, S) ;$ Patriot $(15, I) ;$ Northland $(15, S) ;$ Earliblue $(15, D)$ \\
\hline New Jersey & 3321 & Bluecrop $(50, S)$; Weymouth $(30, \mathrm{D}) ;$ Bluetta $(10, \mathrm{D})$; Duke $(5, \mathrm{I})$; Eliott $(5, \mathrm{~S})$ \\
\hline New York & 486 & Bluecrop $(40, \mathrm{I}) ;$ Blueray $(20, \mathrm{I}) ;$ Patriot $(20, \mathrm{I})$; Berkeley $(10, \mathrm{~S})$; Jersey $(5, \mathrm{D})$ \\
\hline North Carolina & 1580 & Croatan $(60, S) ;$ Murphy $(6, \mathrm{D}) ;$ New Murphy $(5, \mathrm{D}) ;$ Tifblue $(5, S) ;$ O'Neal $(4, \mathrm{I})$ \\
\hline Ohio & 113 & Coville $(25, \mathrm{D})$; Berkeley $(20, \mathrm{I})$; Bluecrop $(15, \mathrm{I})$; Collins $(10, \mathrm{D})$; Jersey $(10, \mathrm{D})$ \\
\hline Oklahoma & 81 & Bluecrop $(30, \mathrm{D}) ;$ Blueray $(30, \mathrm{D})$ \\
\hline Oregon & 668 & Bluecrop $(30, \mathrm{I})$; Berkeley $(25, \mathrm{I})$; Earliblue $(7, \mathrm{D})$; Jersey $(7, \mathrm{D})$ \\
\hline Pennsylvania & 202 & Bluecrop (S); Patriot (I); Spartan (I); Elliott (S); Blueray (S) \\
\hline South Carolina & 159 & Tifblue $(50, \mathrm{D}) ;$ Climax $(20, \mathrm{I}) ;$ Woodard $(5, \mathrm{~S}) ;$ Premier $(5, \mathrm{~S}) ;$ Delite $(5, \mathrm{D})$ \\
\hline Tennessee & 73 & Tifblue $(60, \mathrm{I}) ;$ Climax $(20, \mathrm{I}) ;$ Woodard $(5, \mathrm{D}) ;$ Homebell $(1, \mathrm{D})$ \\
\hline Texas & 526 & Tifblue $(50, S) ;$ Climax $(25, \mathrm{I}) ;$ Brightwell $(10, \mathrm{I}) ;$ Delite $(10, \mathrm{D})$; Premier $(5, \mathrm{~S})$ \\
\hline Vermont & 40 & Bluecrop $(S)$; Berkeley $(S)$; Coville $(S)$; Herbert $(S)$ \\
\hline Virginia & 85 & Bluecrop $(30, \mathrm{I})$; Premier $(8, \mathrm{I})$; Powderblue $(8, \mathrm{I})$; Blueray $(5, \mathrm{~S})$; Collins $(5, \mathrm{D})$ \\
\hline Washington & 486 & Bluecrop $(25, S) ;$ Jersey $(15, S)$; Berkeley $(10, S) ; 1613 \mathrm{~A}(10, \mathrm{I}) ;$ Blueray $(5, \mathrm{D})$ \\
\hline Wisconsin & 2 & Northblue (I); Northcountry (I); Northsky (I); Friendship (I); Patriot (I) \\
\hline \multicolumn{3}{|r|}{ - } \\
\hline British Columbia & 1822 & Bluecrop $(50, \mathrm{I})$ \\
\hline Nova Scotia & 71 & Covillc $(21, S)$; Bluccrop $(17, S)$; Jersey $(13, S)$; Berkeley $(13, S)$; Blueray $(10, S)$ \\
\hline Ontario & 263 & Bluecrop $(70, \mathrm{I})$; Northland $(10, \mathrm{D}) ;$ Elliott $(5, \mathrm{I}) ;$ Berkeley $(5, \mathrm{D}) ;$ Blueray $(5, \mathrm{D})$ \\
\hline Quebec & 81 & Patriot (I); Blueray (S); Bluecrop (S); Berkeley (D); Northland (D) \\
\hline
\end{tabular}

${ }^{*}$ Parentheses following cultivar name show percent of area occupied by the cultipar, and whether the cultivar is increasing $(I)$, stable (S), or decreasing (D) in popularity. 
and is expected to increase (10 states) or remain stable (12 states) in all reporting states but two. Incontrast, 'Jersey' and 'Weymouth', the second- and third-most-planted highbush cultivars, are in decline. Previously, Hanson and Hancock (1990) reported that 'Bluecrop' occupied $32.4 \%$ of the highbush blueberry hectarage worldwide, while 'Jersey' and 'Weymouth' were planted on $18.7 \%$ and $6.0 \%$ of highbush hectarage, respectively. Another notable feature of 'Bluecrop' is its listing as a "top 5" cultivar in 26 states and provinces, ranging from Arkansas in the southern United
States, north to the Canadian provinces, and west to Oregon and Washington. This wide popularity indicates broad climatic and edaphic adaptation of 'Bluecrop'.

The fourth-leading highbush in hectarage, 'Croatan', was listed by only one state, North Carolina, and its hectarage is stable. 'Blueray' was listed on 23 state surveys, but does not seem to be increasing, perhaps due to its inability to be harvested mechanically. Among new cultivars, 'Elliott' is increasing the most, and is currently in fifth place in hectarage.

Based on trend projections, there likely will be a future increase in plantings of the northern highbush cultivars 'Bluecrop', 'Elliott', 'Patriot', 'Spartan', and 'Duke'; and of the half-high cultivars 'Northblue' and 'St. Cloud'. Conversely, the cultivars 'Jersey', 'Weymouth', 'Rubel', 'Berkeley', 'Bluetta', 'Earliblue', 'Northland', 'Collins', 'Murphy', and 'Coville' will probably decline in popularity.

Among rabbiteye cultivars, 'Tifblue' dominates, occupying $40 \%$ of the rabbiteye hectarage (Table 2). It is listed among the top five cultivars in all eight rabbiteye-producing states. However, the percentage of rabbiteye hectarage occupied by 'Tifblue' is less than the $53 \%$ reported for 1989 by Spiers (1990). 'Climax', in second place, also is listed by eight states and is increasing in popularity in four states. 'Bright-well', a relatively new cultivar, occupies third place in rabbiteye plantings and shows a strong increase in popularity. 'Woodard', once a major cultivar, is in rapid decline. 'Premier' and 'Powderblue' are expected to increase in importance in the future, while 'Delite' is declining in all states in which it is grown.

Only two southern highbush cultivars were reported in this survey. 'Sharpblue' is a major cultivar in Florida, while 
'O'Neal' plantings are increasing in North Carolina. Moore's (1993) survey indicated that southern highbush cultivars would show the greatest percentage of growth in plantings of all cultivated blueberries by the year 2000; therefore, the hectarage of these and newer southern highbush cultivars are expected to take a sharp upturn.

Respondents were asked to list new cultivars that show promise in their states/provinces. Eleven northern highbush, six rabbiteye, and nine southern highbush cultivars were listed by one or more respondents (Table 3). Some of these cultivars also appear on the list of major cultivars in other states (Tables 1 and 2).

The most-promising new northern highbush cultivar, based on responses, is 'Duke', which was listed on 11 returns. Preliminary testing indicates that 'Duke' may be similar to 'Bluecrop' in being widely adapted, because it is listed as promising from Arkansas to Ontario and west to Oregon and British Columbia. 'Bluejay', 'Nelson', 'Toro', and 'Patriot' were also listed as promising on several ballots.

Among newer rabbiteye cultivars, 'Briteblue' and 'Brightwell' appear promising across the southern United States, as do the southern highbush 'Georgiagem', 'Cooper', 'Gulfcoast', and 'Blueridge'. 'Sharpblue' and 'O'Neal' are already established cultivars in some states, while 'Reveille' and 'Bladen' are too new to have been evaluated adequately outside of North Carolina.

Several significant changes have occurred in the blueberry cultivar situation in the past decade. Among major changes listed by survey respondents are: Southern highbush increasing in the southern United States; new half-high cultivars being planted in the upper Midwest; a switch to cultivars that can be machine-harvested; a shift to more-hardy cultivars ('Patriot', 'Blueray', and 'Northland') in New England; a shift to earlier-ripening rabbiteye cultivars; and a general trend toward increased plantings of 'Bluecrop', 'Duke', and 'Elliott', with decreased interest in 'Collins' and 'Covill'.

Respondents were asked to list the major genetic limitations ofblueberry cultivars available at present. Limitations reported (in order of frequency oflisting) were: Lack of cold hardiness (11); susceptibility to spring frosts (7); lack of adaptation to high soil $\mathrm{pH}$ (7); lack of upland and heavy soil adaptation (6); lack of adaptation to machine-harvest (5); drought susceptibility (4); early bloom of rabbiteye and southern highbush cultivars (4); poor fruit quality (4); susceptibility to cane blight (4), phytophthora root rot (3), phomopsis rot (3), viruses (2), fusicoccum canker (1), mummyberry (1), and necrotic

Table 3. Promising new blueberry cultivars in North America.

\begin{tabular}{ll}
\hline Cultivar & \multicolumn{1}{c}{ States/provinces } \\
\hline $\begin{array}{l}\text { Northern highbush } \\
\text { Duke }\end{array}$ & Ark., B.C., Conn., Ind., Mich., Mo., N.H., N.J., Ont., Ore, Pa. \\
Bluejay & Conn., Idaho, Ind, Ky., Ohio, Que., Wash. \\
Nelson & Ind., Mich, Mo., N.H., N.J., N.Y., Ore. \\
Toro & B.C., Idaho, N.Y., Ont., Ore. \\
Patriot & Ill., Ky., Mass., Wash., Wis. \\
Elliott & Ill., Mich., Ohio, Okla. \\
Spartan & Conn., Ind., Que. \\
Northblue & Idaho, Minn, Que. \\
Sierra & N.J., N.Y. \\
St. Cloud & Minn. \\
Northsky & Neb. \\
Rabbiteye & \\
Briteblue & Ga., La., S.C., Tenn. \\
Brightwell & La., S.C., Texas \\
Powderblue & La., S.C. \\
Centurion & S.C. \\
Snowtlake & Hla. \\
Windy & Fla. \\
Southern highbush & \\
Georgiagem & Ga., La., Texas \\
Cooper & La., Miss., Texas \\
Gulfcoast & La., Miss. \\
Blueridge & Miss., Va. \\
Cape Fear & La. \\
Sharpblue & Texas \\
O'Neal & Okla. \\
Reveille & N.C. \\
Bladen & N.C. \\
& \\
\hline
\end{tabular}

ringspot (1); poor fruit set (1); and lack of early ripening cultivars with good fruit quality (1). It is noteworthy that several of these limitations are associated with the current trend in North America of expanding blueberry production into nontraditional climatic and soil regions. As blueberry production continues to expand into new areas, cultivar limitations in adaptability are becoming more apparent.

A part of the 1992 survey concerned blueberry research programs in progress. Of 10 areas of blueberry research reported, cultivar testing was listed most often, ongoing in 32 of 35 reporting states and provinces. This high activity in cultivar testing indicates the general perception that blueberry production problems can be addressed best by new superior cultivars. Interest is especially high in identifying cultivars with improved cold hardiness, soil adaptability, and disease and insect resistance.

Despite the need for improved cultivars and the wide interest in testing genetic material, only 10 states/provinces reported involvement in breeding programs. These are: Alaska, Arkansas, Florida, Georgia, Michigan, Minnesota, Mississippi, New Jersey, North Carolina, and British Columbia. Many

\section{'As blueberry production con- tinues to expand into new areas, cultivar limita- tions in adapta- bility are be- coming more apparent."}


of these are cooperative programs with the USDA. Of the 10 breeding programs, five are involved with improvement ofnorthern highbush (Arkansas, Michigan, New Jersey, North Carolina, British Columbia), four with rabbiteye improvement (Florida, Georgia, Mississippi, North Carolina), and five with breeding southern highbush (Arkansas, Florida, Georgia, Mississippi, North Carolina), In several states, dual programs are conducted to improve two or more types of blueberry (Arkansas, Florida, Georgia, Mississippi, North Carolina). The Minnesota program is focused on developing half-high cultivars for the upper Midwest by hybridizing highbush and lowbush. In Alaska, a breeding program has been initiated recently to improve the native species, $V$. ulginosum $\mathrm{L}$.

\section{Future outlook}

The blueberry cultivar situation in North America recently has entered into an era of rapid change. This has been brought about by recent releases of new cultivars and intensified production problems caused by biotic and abiotic agents. The current trend to increase blueberry production in nontraditional climates and soils is revealing a new set of problems and challenges. The best approach to adapting blueberries to varying soils, sites, and pest pressures appears to be through genetic manipulation of the host plant. Much of the current breeding effort is directed toward meeting these challenges.

The blueberry industry of North America has grown rapidly in the past half-century and has potential for even greater expansion in the future. The key to achieving this potential on state, regional, and national levels will be in the availability of superior, adapted blueberry cultivars. Current activities in blueberry breeding instill optimism for the future, but it is imperative that blueberry breeding programs be maintained and sustained if the blueberry industry of North America is to achieve its full potential.

\section{Literature Cited}

Finn, C.E., J.J. Luby, and D.K. Wildung. 1990. Half-high blueberry cultivars. Fruit Var. J. 44:6368.

Hanson, E.J. and J.F. Hancock. 1990. Highbush blueberry cultivars and production trends. Fruit Var. J. 44:77-81.

Lyrene, P.M. 1990. Low-chill highbush blueberries. Fruit Var. J. 44:82-86.

Moore, J.N. 1993. The blueberry industry of North America. Acta Hort. (In press.).

Spiers J.M. 1990. Rabbiteye blueberry. Fruit Var. J. 44:68-72. 